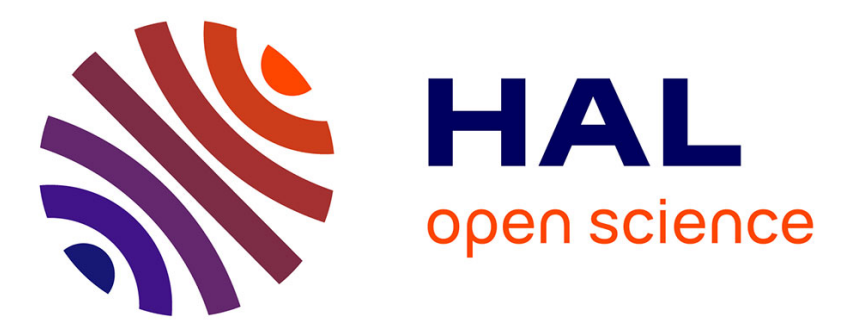

\title{
Operational assessment of access to ART in rural Africa: the example of Kisantu in Democratic Republic of the Congo
}

Sara van Rompaey, Jacques Kimfuta, Pierre Kimbondo, Cecilia Monn, Anne Buvé

\section{To cite this version:}

Sara van Rompaey, Jacques Kimfuta, Pierre Kimbondo, Cecilia Monn, Anne Buvé. Operational assessment of access to ART in rural Africa: the example of Kisantu in Democratic Republic of the Congo. AIDS Care, 2011, 23 (06), pp.686-693. 10.1080/09540121.2010.532538 . hal-00676088

\section{HAL Id: hal-00676088 https://hal.science/hal-00676088}

Submitted on 3 Mar 2012

HAL is a multi-disciplinary open access archive for the deposit and dissemination of scientific research documents, whether they are published or not. The documents may come from teaching and research institutions in France or abroad, or from public or private research centers.
L'archive ouverte pluridisciplinaire HAL, est destinée au dépôt et à la diffusion de documents scientifiques de niveau recherche, publiés ou non, émanant des établissements d'enseignement et de recherche français ou étrangers, des laboratoires publics ou privés. 

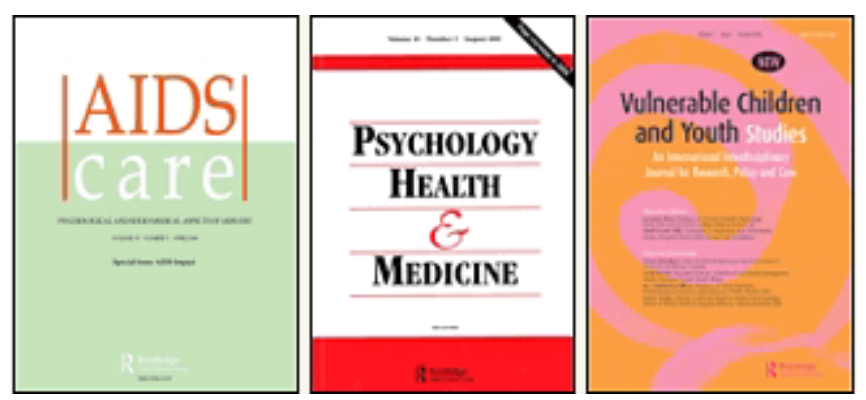

\section{Operational assessment of access to ART in rural Africa: the example of Kisantu in Democratic Republic of the Congo}

\begin{tabular}{|r|l|}
\hline Journal: & $\begin{array}{l}\text { AIDS Care - Psychology, Health \& Medicine - Vulnerable Children } \\
\text { and Youth Studies }\end{array}$ \\
\hline Manuscript ID: & AC-2010-05-0261.R1 \\
\hline Journal Selection: & AIDS Care \\
\hline Keywords: & HIV/AIDS, access, ART, VCT, Democratic Republic of the Congo \\
\hline \multicolumn{2}{|c}{} \\
\hline
\end{tabular}

\section{SCHOLARONE \\ Manuscripts}


Operational assessment of access to ART in rural Africa: the example of Kisantu in Democratic Republic of the Congo"

\section{Abstract}

Despite the availability of large funds and considerable efforts to improve access to ART (Antiretroviral Therapy), coverage of treatment with ART remains low in DRC. We identified the bottlenecks for adults' access to ART in a semi-rural health zone in DRC, compared ART coverage in the urban and rural area and described the outcomes and yield of different HIV testing settings. An operational model was used to examine bottlenecks in the flow of patients. The study period covered the start of the HIV care program in April 2006, until December 2008. An estimated 505 PLWHA (People Living With HIV/AIDS), of whom 201 were in need of ART, lived in the health zone. The proportion of PLWHA in need of ART who were actually receiving ART was estimated at $53 \% .6451$ adults were tested for HIV, 266 of them were HIV positive and 163 accessed the HIV care programme. 106 of the 126 to 159 eligible patients initiated ART. The main bottleneck was situated at HIV detection. Access to the HIV care programme for the patients testing HIV positive was identified as the second biggest bottleneck. $41 \%$ of the PLWHA identified in urban areas accessed the HIV care programme, versus $11 \%$ of the rural PLWHA, showing a serious inequity. The TB (tuberculosis) programme detected $75 \%$ of the total estimated 92 co-infected patients of the health zone. Only $13 \%$ of women testing positive in the PMTCT (Prevention of Mother-To-Child Transmission) programme accessed the HIV care programme, showing that this bottleneck is greatly accentuated in this specific group. By testing all pregnant women and all TB patients in the health zone, $28 \%$ of all PLWHA could potentially be detected in a period of 33 months, showing its great potential in settings with a relatively low HIV prevalence.

\section{Introduction}

Since its independence in 1960, the Democratic Republic of the Congo (DRC) has faced economic decline $^{1}$, resulting in a low per capita GNP, limited reach of government services, and break down of communication systems and infrastructure. In the 2010 index of failed states ${ }^{2}$, DRC is ranked the fifth worst country in the world. DRC is facing enormous challenges to provide health care, including HIV care. Gaps left by the government are filled by numerous non-governmental and faith-based organizations.

HIV prevalence in DRC has recently been estimated at $1.3 \%$.( 1) The Demographic and Health Survey estimates the prevalence in people living in urban and rural areas at 1.9 and $0.7 \%$ respectively.

Despite the availability of large funds and considerable efforts to improve access to ART (Antiretroviral Therapy) ${ }^{3}$, coverage of treatment with ART in DRC is low. The WHO ' 3 by 5 ' target for DRC was 
80000 people receiving ART. The Global Fund's Performance Monitoring Report mentions only 13064 people who were receiving ART on the $30^{\text {th }}$ June $2007^{4}$. With coverage of less than $10 \%$, DRC is classified amongst the worst countries in the world in terms of scaling up. ${ }^{5}$ According to national data, only $4.1 \%$ of all adults have been tested for HIV in a year's time (3), which suggests that lack of HIV testing is an important bottleneck. $70 \%$ of HIV positive patients who started ART are still in therapy 12 months after the initiation. A major obstacle for appropriate ART Delivery Programs is patient loss to follow up. High rates (35\%) of loss to follow-up > 6 months since the last clinic visit have been reported in DRC. Cumulative incidence of death among lost patients is high. ${ }^{6}$ No data are available on the total number of the detected HIV positive people who registered at an HIV care programme, neither about the proportion of eligible patients amongst patients registered and the proportion of eligible patients who initiated ART, in DRC.

The aim of this research is to identify the bottlenecks of access to ART in a health zone in DRC, using an operational model. The study compares the proportion actually on ART with the estimated number in need of ART. It identifies the problems that arise at different steps of an operational flow model, ${ }^{7}$ by evaluating the proportion of HIV positive people who know their HIV status, the proportion of those who access the HIV care programme, the proportion of eligible patients at clinic level and the proportion initiating ART. The study compares access for patients living in the urban and rural areas of the health zone. It compares HIV prevalence, and access to the HIV care programme in patients tested in different testing settings. It evaluates the yield of the different HIV testing sites and estimates their potential to detect an important number of people living with HIV.

\section{Methods}

Setting

Kisantu is a semi-rural health zone in Bas-Congo province with a surface of 240 square kilometres and an estimated total population of 144,395 inhabitants, 73,205 of whom live in the urban area of Kisantu town and 71,190 in rural villages. The main economic activity is subsistence farming $(70 \%$ of the active population) while $20 \%$ of the population make a living with small-scale commercial and other informal activities, and $10 \%$ is employed by the government.

Based on data from the Demographic Health Survey, HIV prevalence in Kisantu is roughly estimated at $1 \%$ for the urban population and $0.4 \%$ for the rural population. The HIV care programme is integrated and centralised in the mission hospital Saint Luc, located in Kisantu town, and managed by the Ministry of Health. No health care providers outside this programme are providing ART.

The programme receives rapid antibody tests, antiretroviral medicines and drugs for opportunistic infections treatment funded by the Global Fund to Fight AIDS, Tuberculosis (TB) and Malaria. 
HIV testing is performed in the hospital, in 2 rural and 3 urban maternity wards, in the TB diagnostic and treatment centre located in the hospital, and in one urban community-based VCT (Voluntary testing and Counselling) centre. The HIV testing site in the hospital receives referrals by clinicians as well as clients who wish to know their HIV status on a voluntary basis. All pregnant women presenting at the ante-natal clinics in the five maternities where a PMTCT (Prevention of Mother-To-Child Transmission) programme is implemented, are advised to be tested for HIV, using an opt-out strategy. Kisantu has 4 TB centres for diagnosis and treatment. Three of them are rural and the fourth is located in the hospital. HIV testing is only available for TB patients treated in the hospital site, according to an opt-out strategy.

CD4 counts are only freely available for TB/HIV co-infected patients. For the other patients, eligibility is based on clinical staging and total lymphocyte count, according to the national guidelines. All patients, whether eligible for ART or not, are asked to visit the HIV clinic every month.

\section{Framework for estimation of patients' flow}

The flow model used in this study is based upon an operational model for the analysis of TB control programmes, developed by MA Piot (1967), who at that time was attached to WHO. ${ }^{8}$ In this study our simplified model has 4 steps (Figure 1).

Figure 1: simplified model for operational flow of PLWHA

To estimate the number of people in need for treatment, the software package Spectrum ${ }^{9}$, recommended by the UNAIDS reference group, was used. The proportion of PLWHA in need of ART and the proportion of new patients needing ART per year were determined using this programme.

PLWHA in need of ART = (PLWHA in community $x$ percentage people in need of ART $)+($ PLWHA in community $x$ percentage new patients needing ART per year $x$ duration of study period in years)

For the comparison of the ART coverage in the rural and urban area of Kisantu, the same operational flow model and definitions are used, taking into account the different HIV prevalence in the urban and rural area.

Data were collected from the beginning of the HIV care program in April 2006 until $31^{\text {st }}$ December 2008.

For the first part of the study, census data of the population of Kisantu health zone, obtained at the database of the Ministry of Health, are used. In the Demographic and Health Survey of 2008 (1), about $50 \%$ of the population of RDC is estimated to be older than 15 years. We used the regional prevalence of $0.7 \%$, observed in Western DRC (1). 


\section{Proportions of patients in different HIV testing sites}

In order to estimate the yield of different types of testing sites like the TB programme and the PMTCT programme, we used the following formula:

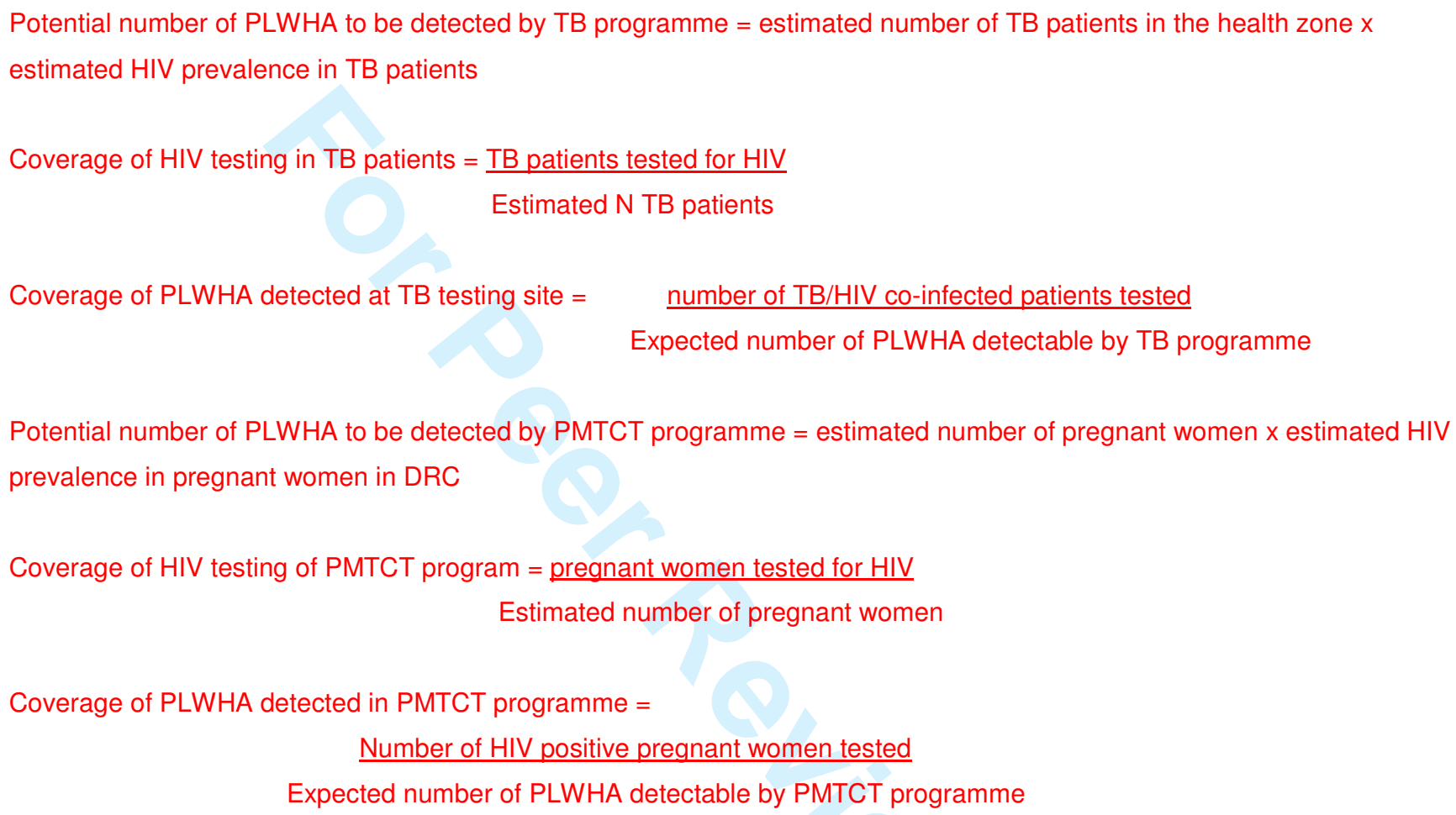

\section{Data collection}

The number and residence (urban or rural or outside of Kisantu health zone) of people tested at each HIV testing site, and the proportion of HIV positive tests results, were collected from the monthly reports of the health zone, the anonymous VCT forms of the hospital and the TB patients' monitoring register.

For all patients who accessed the HIV care programme, the residence of the patient and the initial testing site were extracted from the HIV care programme's registers. The patients' personal files were checked for eligibility and anonymously compiled on another form.

ART eligibility status was checked using the national criteria for initiation of antiretroviral treatment ${ }^{10}$.

The number and residence of patients starting ART were extracted in an anonymous way from the ART register of the HIV care programme. 
All PLWHA with residence outside of Kisantu health zone were excluded from the analysis of the patients' flow, but were included in the evaluation of the performance of different testing sites and the yield of TB and PMTCT programmes.

According to data from the $\mathrm{WHO}^{11}$ tuberculosis report 2009, the national incidence rate of tuberculosis is estimated at 392/100 000 pop/year and the HIV prevalence in incident TB cases at 5.9\%.

The estimation of the number of pregnant women in Kisantu is based on data published in the Demographic Health Survey. In Bas-Congo province, the prevalence of pregnancy is $9.6 \%$ among women between 15 and 49 years. For a population of 144395 inhabitants, 3032 women are estimated to be pregnant at any one time.

According to official reports from Kisantu health zone, the HIV prevalence of pregnant women in the PMTCT programme is $0.6 \%$.

\section{Ethical approval}

The study was approved by the ethical committee of the School of Public Health of the University of Kinshasa.

\section{$\underline{\text { Results }}$}

\section{Proportions of PLWHA in the operational flow}

During the study period an estimated 505 adults in Kisantu health zone were living with HIV, of whom 266 (53\%) were identified in the HIV testing sites and 239 HIV infected adults remained unaware of their condition. 62 people who were identified with HIV during the study period were living outside of Kisantu health zone. Of the 266 PLWHA of Kisantu health zone that were identified, 163 (61\%) accessed the hospital's HIV care programme during the study period. 10 PLWHA who accessed the HIV care programme were living outside Kisantu health zone. 126 of those living in Kisantu health zone who accessed the HIV care programme were identified as eligible and four as non eligible for ART. For 33 patients who were not initiated on ART, eligibility status remained unknown, as their personal files could not be found in the hospital. The exact number of eligible patients is thus between 126 and 159 patients.

106 eligible patients living in Kisantu health zone initiated ART. Between 20 and 53 eligible patients got lost at this step.

$\rightarrow$ Table 1: proportions of adult patients according the different steps in the flow program 
Overall $32 \%(53 \% \times 61 \%)$ of the estimated number of adult PLWHA in the health zone accessed the HIV care programme. According to the outcomes of the analysis with the Spectrum software package, 201 patients were estimated to be in need of ART in Kisantu during the study period. With 106 patients who were initiated on ART, ART coverage of $53 \%$ was reached.

In the urban area of Kisantu, $41 \%$ of the estimated PLWHA accessed the HIV care programme and $65 \%$ of the estimated 145 patients in need initiated ART. In the rural area, $11 \%$ of all PLWHA accessed the HIV care programme and $21 \%$ of the estimated 56 patients in need initiated ART.

\section{Proportions of patients in different HIV testing sites}

6,451 adults have been tested for HIV in the health zone during the study period. 328 of them tested HIV positive, resulting in an average prevalence of $5 \%$ for all testing settings together.

$\rightarrow$ Table 2: comparison of outcomes of different HIV testing sites

The estimated number of TB patients in the health zone is 566 per year, so 1,557 for the whole study period. 92 patients amongst them are estimated to be infected with HIV, of whom the TB programme detected $75 \%$.

The estimated yearly number of pregnant women in the health zone is 3,032 , which means 8,338 pregnant women for the whole study period. 50 pregnant women were estimated to be infected with HIV, meaning that the PMTCT programme detected $48 \%$ of the estimated number of HIV positive pregnant women in the health zone.

The TB and PMTCT programme together could theoretically detect 142 patients, which is $28 \%$ of the estimated 505 PLWHA living in the health zone, as illustrated in table 3.

$\rightarrow$ Table 3: potential and actual coverage of the TB programme and PMTCT programme

\section{Discussion}

\section{Limitations of the study}

There are several aspects of the study design that call for some caution in the interpretation of the results. Firstly, the data used in this study highly depend on the estimation of the prevalence of HIV, TB, and fertility rates of the general population. Secondly, this is a small-scale study with rather small proportions of patients, especially at the later steps of the model. Extrapolation of these data might not 
be accurately representative of a large-scale HIV programme. A large-scale study containing data of different health zones, or a country national level, would be interesting in this respect.

Although the study evaluates how many patients reach the steps of the operational flow within the study period, it does not reveal how much time patients take to proceed to the next step. E.g. an HIV positive person, who is ignorant of his status today, may want to go for testing in a few years' time, when he will become aware of his HIV-related symptoms. The exact outcomes of the drop-offs remain unknown and therefore it cannot be determined in which group of drop-offs the highest mortality occurs, neither which proportion in each group of drop-offs will proceed eventually to the next step. In fact, any definition of loss to follow-up at any step of the flow model can be seen as arbitrary as a patient who is late can never be considered as definitively lost unless he is reported to be dead. However, even if the proportion of dead patients among patients lost to follow-up is unknown, loss to programme can undoubtedly be seen as a program failure indicator.

Furthermore, CD4 counts are not systematically quantified in each patient, which does not allow a precise evaluation of the grade of immunodeficiency and therefore severity of disease in registered patients.

This study provides only quantitative data, but to gain more insight in the determinants behind the awareness and health-seeking behaviour of the population, identified as two important bottlenecks, qualitative studies are needed. Aspects that have not been covered in this study are the quality of counselling and HIV care, children's access to ART, psychosocial follow-up, adherence to ART and prevention. Other studies are needed to cover these aspects.

\section{Proportions of PLWHA in the operational flow}

The estimated ART coverage is much higher in Kisantu (53\%) than nationally (less than 10\%) because in the majority of health zones of DRC the HIV care programme is not implemented, due to insufficient funding.

Poor coverage of HIV testing has been explained in other resource-limited contexts by poor healthseeking behaviour, stigma in society and operational challenges. Apart from two health centres with a PMTCT programme, all testing sites are located in the urban area. Transportation problems are probably the main obstacle for people living in rural areas. In a successful program of scaling up VCT in Kenya ${ }^{12}$, similar findings have been documented: 'The national target number of testing sites has been exceeded, although the target number of sites for each district has not been achieved in the districts in remote or hard-to-reach areas, and a program to increase mobile VCT tries to compensate for this poor access.' In DRC, decentralisation of VCT to the health centres and health posts might be a good solution, but many personnel will have to be trained. Furthermore, it will be difficult to overcome the inequity in access to the HIV care programme, if over time its provision will still remain 
in one central site. According to WHO, many countries suffer from urban concentration of health professionals and rural deficits. ${ }^{13}$ Strategies to decentralise HIV care should be developed, as in Lusikisiki, in rural South-Africa, where a greater proximity and acceptability of services at the clinic level led to faster enrolment of people receiving treatment. ${ }^{14}$

The second biggest bottleneck, being access to the HIV care programme for those who have been identified with HIV, could be regarded as more crucial because the HIV care programme is not capable of treating all patients that are detected. The explanation is probably multifactoral. It may be due to a poor referral system between the testing sites and the HIV care programme or related to the health seeking behaviour of people tested HIV positive. A high proportion of PLWHA who accessed the HIV care programme is eligible, which means that people are detected and/or registered when they may be aware of their illness. The fact that ART coverage in all eligible patients in the health zone is better than the PLWHA coverage of the HIV care programme, suggests that the HIV care programme selected the more severe 'eligible' cases.

\section{Outcomes of different HIV testing services}

The good flow of the TB/HIV co-infected patients to the HIV care programme and the high loss to follow up of HIV infected pregnant women, are probably explained by the patients' awareness of their health status. This study shows that tuberculosis control programmes have a great potential of identifying persons infected by HIV in settings with low HIV prevalence: with only a low percentage of TB patients who have been tested for HIV, a high proportion of HIV patients of the health zone are picked up by the programme, because health care worker-initiated settings of hospitalised patients and persons suspected of having tuberculosis are ideal settings in which to identify large numbers of persons with advanced HIV infection(12). The high uptake of HIV testing in the maternity departments and the TB programme is most likely linked to their opt-out strategy. Looking at the proportions that accessed the HIV care programme, the identified bottleneck also seems to be linked to operational aspects of HIV the testing site. The community-based VCT site (with 75\% access of HIV positive patients to the HIV care programme) routinely performed active follow-up of those tested positive. With the observed HIV prevalence of $0.6 \%$ in pregnant women, the PMTCT programme could theoretically detect $10 \%$ of all PLWHA, by testing $11.6 \%$ of the total adult population. However, the prevalence we observed might be under-estimated as in Bas-Congo province, $2 \%$ of women in PMTCT programmes were tested HIV positive ${ }^{15}$. On the other hand, according to a survey of UNAIDS in sub-Saharan Africa ${ }^{16}$, the HIV prevalence of women attending ante-natal clinics is 1.25 times higher than the prevalence obtained by a demographic health survey, which would for Bas-Congo would mean $0.87 \%$ of pregnant women. 
The opt-out strategy in the PMTCT programme has only a small impact on the health status of the HIV positive mothers in Kisantu, because a limited proportion of them obtain HIV care, as has been shown in other studies as well ${ }^{1718}$. Improving the referral system between PMTCT programs and the HIV care programme is a priority. In the TB clinic, patients had regular appointments to collect the TB drug, and a detailed register allowed tracking of each co-infected patient. DOTS has been used now for many years to provide successful anti-tuberculosis treatment to millions of patients in poor countries of the world, and the ART programme may benefit from many of the established concepts of a TB programme. ${ }^{19}$ Based on the better performance of TB programmes in detection, referral and care of people found to have HIV infection, other programmes like those of STI control and reproductive health care would benefit from a more standardized approach with an opt-out strategy of HIV testing and a more rigorous referral and treatment protocol.

We also suppose that TB patients who suspect they are co-infected with HIV may be more likely to seek care at the TB clinic of the referral hospital, the only TB treatment centre that performs HIV testing. Alternatively, the prevalence of HIV in TB patients may be substantially higher in Kisantu (15\%) than the national numbers presented by WHO $(5.9 \%)$, which would increase the actual yield of the TB programme.

In conclusion, the model we used allowed us to identify two important bottlenecks of access to ART, and helps to decide on which approach to adopt to improve access. The probability that a patient does proceed from one step to the next is a measure of the performance of different disease control activities. Poor coverage of HIV testing has been detected in other studies, but more research is required to discover the exact underlying causes for the high loss to follow-up of people with a positive HIV test result. Further investigation could identify weaknesses in the referral system of the programme, patients' possible denial of the test result, adherence to an alternative care circuit or death. Drop-offs at different levels have not only been observed in ART programs, but also in studies of control of sexually transmitted diseases ${ }^{20}$ and tuberculosis ${ }^{21}$.

Given the low rate of loss to follow-up at all steps of patients with TB/HIV co-infection, who benefit from a rigorous approach, we think that the way forward for other disease control programmes is to integrate HIV care in a standardized way. Improving the referral system between PMTCT programs and the HIV care programme is a priority. This study takes into account all activities related to the HIV care program, and gives therefore a realistic overview of the strengths and weaknesses at each level. Loss to follow-up at any step of the programme is a crucial indicator of failure of programme performance in tracking the outcomes of care. 


\section{$\underline{\text { References }}$}

${ }^{1}$ Enquête Démographique et de Santé, République Democratique du Congo 2007. Ministère du Plan avec la collaboration du Ministère de la Santé, Kinshasa, République Démocratique du Congo, August 2008

${ }^{2}$ Failed States Index 2010, a sixth annual collaboration between Foreign Policy and The Fund for Peace, accessible on: http://www.foreignpolicy.com/articles/2010/06/21/2010_failed_states_index_interactive_map_and_rankings

${ }^{3}$ Rapport national de situation à l'intention de I'UNGASS, République démocratique du Congo, janvier - juillet 2007

${ }^{4}$ Global Fund Performance Monitoring Report DRC, $6^{\text {th }}$ November 2007

${ }^{5}$ Report on the global AIDS Epidemic, Joint United Nations Programme on HIV/AIDS, 2006

${ }^{6}$ Atibu Losoma, J., Kiumbu, M., Azinyue, I., Mukumbi, H., Ryder' R. (2009). Losses to follow-up in 3 Central African country non-PEPFAR ART delivery programs. Abstract at IAS conference.

${ }^{7}$ Dujardin, B. et al. (1997). Editorial: Tuberculosis control: did the programme fail or did we fail the programme? Tropical Medicine and International Health, Volume 2 no 8 pp 715-718

${ }^{8}$ Piot, M.A. (1967). A simulation model for case finding and treatment in tuberculosis control program. WHO/TB/Technical Information, WHO, Geneva. pp. 67-53.

${ }^{9}$ Stover et al. (2004). Projecting the demographic consequences of adult HIV prevalence trends: the Spectrum Projection Package. Sex Transmiss Inf; 80 Suppl 1:114-18

${ }^{10}$ Guide national de traitement de l'infection à VIH par les antirétroviraux. République Démocratique du Congo, Ministère de la Santé, Programme National de Lutte contre le SIDA et IST (PNLS). March 2008.

11 Global tuberculosis control - epidemiology, strategy, financing. WHO report 2009

${ }^{12}$ Marum, E., et al. (2006). Scale-up of Voluntary HIV counseling and Testing in Kenya., JAMA Vol.296 No. 7

${ }^{13}$ World Health Organisation (WHO) Health worker shortages and the response to AIDS. Geneva: WHO, (2006). Retrieved from: http://www.who.int/hiv/pub/advocacy/ttr/en/index.html. Accessed 28 April 2009.

${ }^{14}$ Bedelu, M., et al. (2007). Implementing Antiretroviral Therapy in Rural Communities: The Lusikisiki Model of Decentralised HIV/AIDS Care, JID:196 (suppl 3)

${ }^{15}$ Rapport d'activités 2007 du PNLS, Democratic Republic of the Congo

${ }^{16}$ Comparing adult ante-natal clinic based HIV prevalence with prevalence from national population based surveys in subSaharan Africa. UNAIDS, 2007

${ }^{17}$ Kumar, A., et al. (2008). Follow-Up of HIV-Infected Women Diagnosed by Antenatal Screening in Barbados from $1996-$ 2004. AIDS PATIENT CARE and STDs, Volume 22, number 9

${ }^{18}$ Manzi, M., et al. (2005). High acceptability of voluntary counseling and HIV-testing but unacceptable loss to follow up in a prevention of mother-to-child HIV transmission programme in rural Malawi: scaling-up requires a different way of acting., Tropical Medicine and International Health, Volume 10 NO 12 PP $1242-1250$

${ }^{19}$ Libamba E,et al. (2005) Scaling up antiretroviral therapy in Africa: learning from tuberculosis control programmes--the case of Malawi. Int J Tuberc Lung Dis.9(10):1062-71. 
${ }^{20}$ Buvé, A., et al. (2001) How many patients with a sexually transmitted infection are cured by health services? A study from Mwanza region, Tanzania. Tropical Medicine and International Health, volume 6 no 12 pp 971-979

${ }^{21}$ Dujardin, B., et al. (1997) Tuberculosis control: did the programme fail or did we fail the programme? Tropical Medicine and International Health, volume 2 no 8 pp 715-718 
Health Sciences

Page 12 of 14

Figure 1: simplified model for operational flow of PLWHA, page 3

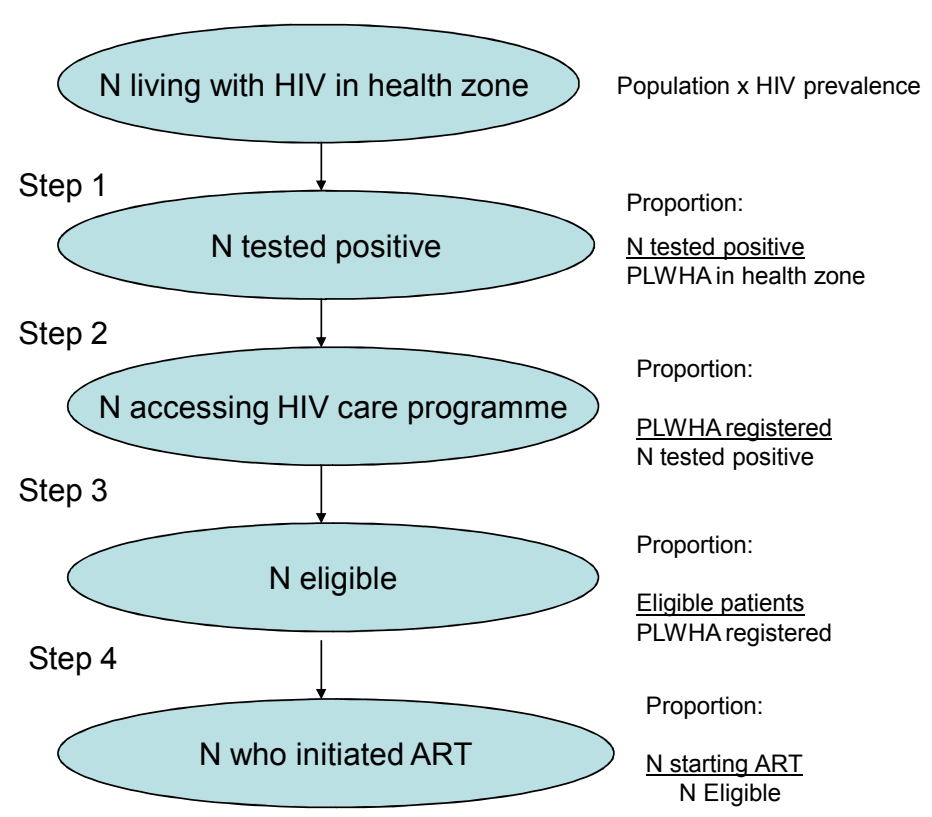

http://mc.manuscriptcentral.com/ac-phm-vcy 
Table 1: proportions of adult patients according the different steps in the flow program, page 5

\begin{tabular}{|l|c|c|c|}
\hline \multicolumn{1}{|c|}{ Step } & $\begin{array}{c}\text { Overall number of persons } \\
\text { living in Kisantu health zone } \\
\text { (n and \% of } \mathbf{n} \text { PLWHA in } \\
\text { previous step) }\end{array}$ & Urban & Rural \\
\hline PLWHA in community & 505 & $224(61 \%)$ & 141 \\
\hline Step1: PLWHA tested + & $266(53 \%)$ & $148(66 \%)$ & $15(30 \%)$ \\
\hline $\begin{array}{l}\text { Step 2: Access to HIV care } \\
\text { programme }\end{array}$ & $163(61 \%)$ & Between 113 and 145 \\
\hline Step 3: In need of HAART & Between 126 and 159 & between 13 and 14 \\
$(87-93 \%)$
\end{tabular}

Table 2: comparison of outcomes of different HIV testing sites, page 6

\begin{tabular}{|c|c|c|c|c|c|}
\hline & $\begin{array}{l}\text { Hospital testing } \\
\text { site } \\
\text { ( } n+\text { and \% of } n \\
\text { PLWHA in } \\
\text { previous step) }\end{array}$ & $\begin{array}{l}\text { Community VCT } \\
\text { ( } n+\text { and } \% \text { of } n \\
\text { PLWHA in } \\
\text { previous step) }\end{array}$ & $\begin{array}{c}\text { PMTCT } \\
\text { programme } \\
(\mathbf{n}+\text { and } \% \text { of } n \\
\text { PLWHA in } \\
\text { previous step) }\end{array}$ & $\begin{array}{l}\text { TB programme } \\
\text { ( } n+\text { and \% of } n \\
\text { PLWHA in } \\
\text { previous step) }\end{array}$ & $\begin{array}{c}\text { Total } \\
\text { ( } \mathrm{n}+\text { and } \% \text { of } n \\
\text { PLWHA in } \\
\text { previous step) }\end{array}$ \\
\hline $\mathrm{N}$ tested & 1125 & 699 & 4152 & 475 & 6451 \\
\hline N HIV + & $195(17 \%)$ & $40(6 \%)$ & $24(0.6 \%)$ & 69 (15\%) & $328(5 \%)$ \\
\hline $\begin{array}{c}\text { Number } \\
\text { accessing HIV } \\
\text { care programme }\end{array}$ & 71 (36\%) & 30 (75 \%) & $3(13 \%)$ & 69 (100\%) & 173 (53\%) \\
\hline $\begin{array}{l}\text { Proportion of all } \\
173 \text { patients who } \\
\text { accessed the HIV } \\
\text { care programme }\end{array}$ & $41 \%$ & $17 \%$ & $1.7 \%$ & $40 \%$ & $\mathrm{~N} / \mathrm{A}$ \\
\hline
\end{tabular}

Table 3: potential and actual coverage of the TB programme and PMTCT programme, page 6

\begin{tabular}{|l|c|c|c|c|}
\hline & \multicolumn{2}{|c|}{ TB programme } & \multicolumn{2}{c|}{ PMTCT programme } \\
\hline & $\begin{array}{c}\text { Estimation of } \\
\text { potential yield }\end{array}$ & $\begin{array}{c}\text { Actual coverage } \\
\text { (n and \% of potential } \\
\text { yield })\end{array}$ & $\begin{array}{c}\text { Estimation of } \\
\text { potential yield }\end{array}$ & $\begin{array}{c}\text { Actual coverage } \\
\text { (n and \% of potential } \\
\text { yield) }\end{array}$ \\
\hline $\begin{array}{l}\text { Total number of people } \\
\text { reached by the } \\
\text { programme }\end{array}$ & 1557 & $742(48 \%)$ & 8338 & $6721(80 \%)$ \\
\hline $\begin{array}{l}\text { Total number of people } \\
\text { tested for HIV }\end{array}$ & N/A & 475 & N/A & 4175 \\
\hline
\end{tabular}




\begin{tabular}{|l|l|l|l|l|}
\hline $\begin{array}{l}\text { number of HIV positive } \\
\text { patients }\end{array}$ & 92 & $69(75 \%)$ & 50 & $24(48 \%)$ \\
\hline
\end{tabular}

